\title{
Estrutura da representação social do cuidado familiar com idosos hipertensos
}

\author{
Social representation structure of family care of hypertensive elderly
}

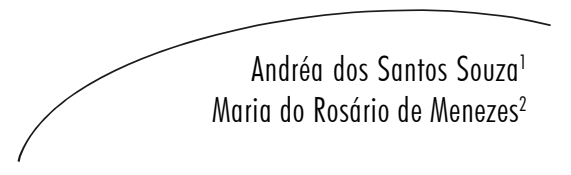

\section{Resumo}

Estudo fundamentado na Teoria das Representações Sociais e na Teoria do Núcleo Central, com objetivo de identificar o núcleo central e o sistema periférico da representação social do cuidado prestado por familiares a idosos hipertensos. Participaram da pesquisa 100 cuidadores residentes no município de Jequié-BA. Os dados foram coletados no domicílio destes, mediante questionário e Teste de Associação Livre de Palavras. Para análise utilizou-se, respectivamente, procedimento estatístico e o software EVOC 99. De acordo com o senso comum, sal, alimentação, não deixar passar raiva e remédio são os elementos representativos do provável núcleo central. A família tem assumido o papel de primeiro recurso disponível para atender às necessidades de saúde dos seus membros idosos, cabendo à enfermagem incluí-la como sua cliente e parceira.

\section{Abstract}

Study based on the Social Representation Theory and on the Central Nucleus Theory aiming to indentify the central nucleus and the peripheral system of the social representation structure of care provided for family members to

Universidade Estadual do Sudoeste da Bahia, Faculdade de Enfermagem de Jequié, Departamento de Saúde. Jequié, BA, Brasil.

2 Universidade Federal da Bahia, Escola de Enfermagem, Departamento de Enfermagem Médico-Cirúrgica. Salvador, BA, Brasil.

Artigo baseado na dissertação de mestrado de Souza AS, defendida na Escola de Enfermagem da Universidade Federal da Bahia, em 2005. Orientadora, Prof ${ }^{a} \operatorname{Dr}^{a}$ Maria do Rosário de Menezes.

Correspondência / Correspondence

Andréa dos Santos Souza

Av. Presidente Vargas, 822, Jequiezinho,

45205-000 Jequié, BA, Brasil

E-mail: andreasouza_75@yahoo.com.br

Palavras-chave:

Relações familiares.

Cuidadores.

Assistência

Domiciliar. Idoso

fragilizado.

Hipertensão.

Família. Idoso

hipertenso.

Jequié-BA 
hypertensive elderly. One hundred caregivers residents in the municipality of Jequié, state of Bahia, participated in the research. Data were collected in their homes, by questionnaire and Free Words Association Testing. For analysis it was used, respectively, statistical procedure and the software EVOC 99. According to common sense, salt, food, not getting anger and medicine are the representative elements of likely core. The family has assumed the role of the first resource available to meet the health needs of their elderly members, while the nursing include it as its customer and partner.
Key words: Family relations. caregivers. Home nursing. Frail elderly. Hypertension. Family. Hypertensive elderly. Jequié city
INTRODUÇÃO

A redução das taxas de natalidade e fecundidade, propiciada pelo avanço tecnológico na medicina e maior acesso aos serviços de saúde, tornou possível um aumento da expectativa de vida, seguida de envelhecimento com longevidade. De acordo com o último censo, os idosos já representavam $8,6 \%$ da população brasileira. No município de Jequié-BA, este percentual é ainda superior: $9,6 \%$ da população têm idade igual ou superior a 60 anos. ${ }^{1}$

Esta transição demográfica destacada trouxe também mudanças significativas no cenário epidemiológico, tornando necessário acrescentar as ações de vigilância às doenças infecto-contagiosas, as ações de vigilância às doenças crônicas não-transmissíveis, alocando uma parcela significativa dos recursos do setor saúde para o controle de patologias como a hipertensão arterial (HA), o diabetes mellitus e as neoplasias, que se destacam como importantes causas de morbimortalidade.
A HA é considerada uma das doenças mais frequentes em idosos e o aumento de sua prevalência é proporcional à idade. ${ }^{2}$ Dados resultantes de inquérito realizado em 17 capitais brasileiras e Distrito Federal revelaram que a prevalência de hipertensão nas pessoas com idade igual ou superior a 60 anos variou entre 39 a $59 \% .^{3}$

Mas, apesar de a HA ser altamente prevalente nessa população, grande parte dos idosos acometidos por essa doença tem uma vida normal quando consegue manter a pressão sob controle. Todavia, os brasileiros acometidos por acidente vascular encefálico (AVE) e as vítimas de infarto agudo do miocárdio apresentam hipertensão associada. Dessa forma, a doença constitui importante problema de saúde pública, pois representa um dos mais importantes fatores de risco para os eventos cardiovasculares.

Consideramos, assim, pertinente empreender esforços para incrementar os cuidados prestados às pessoas idosas hipertensas, pois a redução dos níveis da pressão arterial implica melhor qualidade de vida para os 
idosos, baixo risco para o desenvolvimento de complicações, menor custo em saúde para o Estado e menor desgaste do cuidador familiar.

As alterações fisiológicas provenientes do processo de envelhecimento contribuem para o aumento da pressão arterial, dentre as quais se destacam: a deposição de lipídeos e cálcio nos vasos, a redução da quantidade de óxido nítrico liberado pelo endotélio, a perda da elasticidade e o aumento da resistência vascular. ${ }^{4}$

Outro aspecto relevante é que a diminuição da acuidade auditiva, a demência e a depressão dificultam a coleta de informações e, consequentemente, a construção de um plano assistencial adequado para o idoso. Quanto ao tratamento medicamentoso, este deve ser rigorosamente selecionado, já que nesta fase do ciclo vital o metabolismo de eliminação das drogas é lento, devido ao desgaste sofrido pelo fígado e rins, podendo haver exacerbada manifestação dos efeitos colaterais dos anti-hipertensivos. Associam-se a estes os problemas sociais e econômicos, provenientes do envelhecimento, que tendem a agravar e/ou dificultar o controle da HA, quais sejam: a viuvez, a aposentadoria, a perda dos amigos e os escassos recursos financeiros, que diminuem a adesão ao tratamento medicamentoso e à dieta prescrita.

As diretrizes para o tratamento da $\mathrm{HA}$ apontam dois métodos terapêuticos: orientações, objetivando a mudança do estilo de vida, e a utilização de fármacos. ${ }^{5}$ Para tanto, preconiza-se uma abordagem multiprofissional ao hipertenso, constituída por médicos, enfermeiros, técnicos e auxiliares de enfermagem, nutricionistas, psicólogos, assistentes sociais, educadores físicos, farmacêuticos e agentes comunitários de saúde. ${ }^{5}$

O acesso às informações e medicamentos tem se mostrado importante, mas não suficiente para permitir o controle da hipertensão, pois as pessoas trazem consigo experiências e conhecimentos prévios que influenciam sua maneira de agir perante esta doença.

O conhecimento construído coletivamente transforma a realidade, porém a mudança só ocorre se a necessidade for sentida pelo indivíduo. ${ }^{6}$ Portanto, envolve questões culturais, percepções e experiências individuais acerca do fenômeno. Dessa forma, a família pode ser considerada como um significativo agente influenciador no seguimento das orientações terapêuticas, pois os valores, as crenças e os hábitos de vida são construídos por meio dos processos comunicacionais e solidificados no ambiente familiar.

Assim, podemos inferir que, a despeito das transformações significativas ocorridas na família, esta ainda se constitui em um importante locus intergeracional, onde seus membros influenciam e são influenciados pelas concepções que têm acerca de saúde e doença e das formas de tratamento adotadas. Nesse sentido, é pertinente a afirmativa de Boehs: " "[...] o cuidado, essência da enfermagem, não éporém exclusivo da mesma, a família tam- 
bém cuida, baseada nas suas próprias experiências, decorrentes de conbecimentos populares oriundos de profissionais de saúde". E, por vezes, costuma haver discordância entre o sistema de cuidados popular e profissional. ${ }^{8}$

Por ser a HA uma doença crônica, o tratamento perdurará por toda a vida. Isso implica dizer que é necessária não apenas a orientação, mas uma contínua motivação, em que estarão envolvidos a equipe de saúde, o cliente e sua família.

Nesse contexto, temos uma população longeva, com elevada prevalência de HA, que necessita de apoio (cuidado) familiar para a condução de seu tratamento, seja para aquisição de medicamentos, acompanhamento às consultas e exames, preparo das refeições, reforços às orientações, seja para encaminhamento ao hospital em situações de crise hipertensiva. Esse apoio familiar costuma ser prestado, com maior frequência, pela filha, pela irmã ou neta do idoso (a), chamadas de cuidadoras. ${ }^{9}$

O processo de cuidar dessas mulheres parece ser norteado não por informações transmitidas por profissionais, mas por informações transformadas de acordo com sua capacidade cognitiva, a partir de sua convivência e experiência com o problema.

Desse modo, este estudo, embasado na Teoria das Representações Sociais, se preocupou em desvelar a prática cotidiana do cuidado com idosos hipertensos prestado por seus familiares, norteados por um co- nhecimento socialmente elaborado e partilhado, denominado senso comum.

A relevância da apreensão desse conhecimento, elaborado mediante processos sociocognitivos, está na sua capacidade de orientar práticas que direta ou indiretamente influenciam na aderência do idoso hipertenso ao tratamento preconizado pelos profissionais de saúde.

A partir destas considerações e reflexões provenientes da prática profissional e convivência familiar com idosos hipertensos, emergiram alguns questionamentos, os quais nortearam este estudo: quem são os familiares responsáveis pelo cuidado com idosos hipertensos? Qual a Representação Social que estes elaboram sobre o cuidado com idosos hipertensos? $\mathrm{Na}$ tentativa de respondê-las, adotamos como objetivos: identificar o núcleo central e o sistema periférico das Representação Social do cuidado prestado a idosos hipertensos por seus familiares, bem como determinar o perfil sociodemográfico e de saúde destes.

Dessa maneira, acreditamos que o presente estudo torna-se relevante e oportuno à medida que aumentam a população de idosos e também a prevalência da HA e suas complicações, exigindo práticas de saúde mais eficazes. Pensamos que a apreensão do conhecimento circulante no universo consensual dos familiares de idosos hipertensos poderá possibilitar a (re)orientação do planejamento da assistência a essa clientela, considerando a família como cliente e parceira da enfermagem. 


\section{METODOLOGIA}

Trata-se de um estudo descritivo, de natureza quantitativa, fundamentado na Teoria das Representações Sociais (TRS) e na Teoria do Núcleo Central (TNC).

Moscovici ${ }^{10}$ conceitua as Representações Sociais (RS) como "[...] um conjunto de conceitos, proposiçôes, originadas na vida cotidiana, no curso das comunicaçôes interpessoais [...] podem também ser vistas como a versão contemporânea do senso comum", que emergem dos processos comunicacionais diários entre os indivíduos.

A representação pode ainda ser concebi$\mathrm{da}$, segundo Jodelet, ${ }^{11}$ como "[...] uma forma de conhecimento socialmente elaborada epartilhada, tendo uma orientação prática e concorrendo para a construção de uma realidade comum a um conjunto social".

Em caráter complementar à "grande teoria” proposta por Moscovici, ${ }^{10} \mathrm{Abric}^{12}$ organizou a Teoria do Núcleo Central, com o objetivo de detalhar a estrutura das RS. Para Abric, o conteúdo da representação está organizado em sistema central (estável, rígido, consensual) e em sistema periférico (mutável, individualizado), dispostos em torno daquele.

A utilização da TRS como base teórica associa-se a sua adequação para desvendar o pensamento da sociedade presente acerca de um objeto compartilhado na vida cotidiana, que, neste caso específico, foi o conhecimento socialmente construído e apropriado por familiares acerca do cuidado com idosos hipertensos.
O bairro INOCOOP, eleito para o desenvolvimento do estudo, fica situado na periferia de Jequié, município localizado no sudoeste da Bahia, a $360 \mathrm{~km}$ da capital, Salvador. A escolha do bairro esteve vinculada a aspectos como: ter organizado e em pleno funcionamento o Programa de Saúde da Família, facilitando a localização e o acesso aos sujeitos e, atuar como campo de ensino, pesquisa e extensão para estudantes de graduação e pós-graduação da Universidade Estadual do Sudoeste da Bahia.

Quanto aos sujeitos, foram incluídos os que preencheram os seguintes critérios: aceitar participar voluntariamente da pesquisa, conforme exigido pela Resolução CONEP $n^{\circ} 196 / 96,{ }^{13}$ encontrar-se em condições psicológicas de responder as questões e ser responsável pelo cuidado ao idoso hipertenso por um período mínimo de um ano. A amostra estabelecida foi de aproximadamente $30 \%$ dos 320 cuidadores residentes na área. Desse modo, participaram do estudo 100 familiares cuidadores identificados pelos Agentes Comunitários de Saúde, atuantes nas duas Equipes de Saúde da Família do bairro escolhido para investigação.

Após aprovação pelo Comitê de Ética em Pesquisa da SESAB (Protocolo 011/ 2004), foram utilizados para a coleta de dados dois instrumentos, ambos aplicados pela pesquisadora, no domicílio dos cuidadores, no período de abril a junho de 2004. O primeiro deles, um questionário, constava de perguntas fechadas que objetivavam traçar o perfil sociodemográfico e clínico dos sujeitos, tipo: sexo, idade, grau de escolari- 
dade, estado civil, ocupação, religião, grau de parentesco com o idoso, tempo que cuida do idoso, número de filhos, renda familiar média e problemas de saúde referidos. Concluída esta primeira etapa, prosseguimos aplicando o Teste de Associação Livre de Palavras (TALP), visando a identificar o núcleo central e o sistema periférico da representação do cuidado prestado por familiares a idoso hipertensos.

Para Sá, ${ }^{14}$ o TALP é um método fundamentado em aspectos teóricos da psicanálise que "permite a atualização de elementos implícitos ou latentes que seriam perdidos ou mascarados nas producōes discursivas [...] pousa no princípio de pedir ao sujeito para efetuar ele mesmo sobre sua própria produção um trabalho cognitivo de análise, de comparação de bierarquização". Para facilitar a coleta, familiarizamos cada sujeito com o método e após, solicitamos que evocassem cinco palavras que viessem imediatamente à mente ao ouvir a seguinte frase utilizada como estímulo indutor: cuidar de um idoso com pressão alta. As respostas foram registradas e, na sequência, foi pedido que as hierarquizassem, ou seja, que as enumerassem por ordem de importância.

As informações provenientes do questionário receberam tratamento estatístico, sendo apresentadas em números absolutos e percentuais simples. Quanto aos dados coletados a partir da técnica de associação livre de palavras, estes foram submetidos a uma análise estrutural, pelo processamento no software EVOC 99. Esse recurso informático permitiu identificar a representação do cuidado com idosos hipertensos, apon- tando elementos do núcleo central e do sistema periférico, com base na frequência de ocorrência das palavras evocadas e da média de ocorrência de cada palavra em função da ordem de evocação.

\section{RESULTADOS E DISCUSSÃO}

Supomos que para melhor compreendermos a representação de um objeto, é necessário conhecermos quem o representa. Nessa perspectiva, a partir dos dados obtidos nos questionários e apresentados na tabela 1, observamos que a grande maioria das pessoas que cuida do idoso hipertenso é do sexo feminino (82\%), em idade adulta, ou meia-idade. Porém, é grande o número de jovens cuidadoras (16\%), o que significa dizer que esta responsabilidade tem sido atribuída à mulher ainda na mocidade. Também é notório que as mulheres cuidam ao longo de seu desenvolvimento humano, reduzindo seu papel de cuidadora apenas quando muito idosa, pois já se apresenta frágil, necessitando também de cuidados.

As adolescentes cuidadoras de idosos hipertensos geralmente são suas netas, que não optaram por assumir tal papel, mas foram inseridas nele pelo contexto social, político, cultural e econômico em que vivem.

Os homens, neste estudo (18\%), mostraram exercer mais tardiamente o seu papel de cuidador, iniciando-o a partir dos 26 anos e, mais frequentemente, na velhice, "tomando conta" do cônjuge. 
Tabela 1 - Distribuição por faixa etária e sexo dos familiares cuidadores de idosos hipertensos, residentes em um bairro periférico do município de Jequié -BA, 2004.

\begin{tabular}{cccc}
\hline Faixa Etária /Sexo & Masculino & Feminino & Total \\
\hline $16-25$ anos & 00 & 16 & 16 \\
$26-35$ anos & 05 & 15 & 20 \\
$36-45$ anos & 02 & 15 & 17 \\
$46-55$ anos & 00 & 09 & 09 \\
$56-65$ anos & 04 & 16 & 20 \\
$66-75$ anos & 06 & 07 & 13 \\
$76-85$ anos & 01 & 03 & 04 \\
86 anos e + & 00 & 01 & 01 \\
Total & 18 & 82 & 100 \\
\hline
\end{tabular}

Fonte: Questionário aplicado aos familiares cuidadores de idosos hipertensos, residentes em um bairro periférico do município de Jequié-BA, 2004.

Comparando os dados apresentados neste estudo com os da literatura que abordam o cuidado de idosos, ${ }^{15-18}$ observamos que este segue a forte característica cultural, qual seja, o predomínio das mulheres como gerenciadoras do cuidado.

Em relação ao grau de parentesco com o idoso, o quadro 1 demonstra que 44 dos cuidadores são filhos(as); 31, cônjuges; 12 , netos(as); 13, familiares consanguíneos ou sociais diversos: sobrinha, cunhada, vizinho, irmão, nora e mãe. Entre os filhos cuidadores, seis são homens e 38 mulheres.
Dos cônjuges, oito são esposos e 23 são esposas; e entre os netos, um é do sexo masculino e 11 são do sexo feminino.

Constatamos que filhas e cônjuges contribuem em maior número com o cuidado de idosos, qualquer que seja o grau de dependência destes. Os motivos que levam os filhos a se responsabilizarem por seus pais são múltiplos, e incluem o dever moral, a responsabilidade filial, a gratidão, a reciprocidade, o amor, o cumprimento de um mandamento bíblico, entre outros. 
Quadro 01 - Distribuição das variáveis sociodemográficas e de saúde investigadas em familiares cuidadores de idosos hipertensos, residentes em um bairro periférico do município de Jequié - BA, 2004.

\begin{tabular}{|c|c|c|c|c|c|}
\hline VARIÁVEIS & $\mathrm{N}^{\mathrm{o}}$ & VARIÁVEIS & $\mathrm{N}^{\mathrm{o}}$ & VARIÁVEIS & $\mathrm{N}^{\mathrm{o}}$ \\
\hline $\begin{array}{c}\text { No DE FILHOS } \\
\begin{array}{c}\text { Nenhum } \\
1-3 \\
4-6 \\
7-9 \\
10 \text { ou }+\end{array}\end{array}$ & $\begin{array}{l}25 \\
36 \\
19 \\
10 \\
10\end{array}$ & $\begin{array}{l}\text { OCUPAÇÃO } \\
\text { Do lar } \\
\text { Aposentado (a) } \\
\text { Estudante } \\
\text { Desempregado } \\
\text { Doméstica } \\
\text { Outros }\end{array}$ & $\begin{array}{l}60 \\
10 \\
10 \\
04 \\
04 \\
12\end{array}$ & 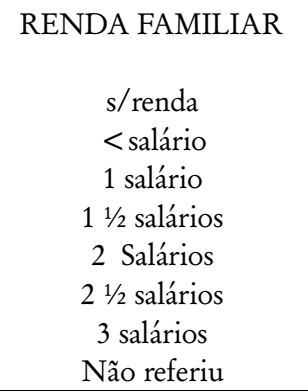 & $\begin{array}{l}01 \\
08 \\
56 \\
05 \\
24 \\
02 \\
03 \\
01\end{array}$ \\
\hline $\begin{array}{l}\text { GRAU DE } \\
\text { PARENTESCO } \\
\text { Filho(a) } \\
\text { Cônjuge } \\
\text { Neto(a) } \\
\text { Irmão(ã) } \\
\text { Vizinho(a) } \\
\text { Nora } \\
\text { Sobrinha } \\
\text { Mãe } \\
\text { Cunhada }\end{array}$ & $\begin{array}{l}44 \\
31 \\
12 \\
03 \\
03 \\
03 \\
02 \\
01 \\
01\end{array}$ & $\begin{array}{c}\text { PROBLEMAS DE } \\
\text { SAÚDE } \\
\text { Hipertensão Arterial } \\
\text { Artropatias/Articulares } \\
\text { Cefaléia } \\
\text { Oftalmológicos } \\
\text { Gástricos } \\
\text { Diabetes Mellitus } \\
\text { Outros } \\
\text { Nenhum }\end{array}$ & $\begin{array}{l}24 \\
20 \\
07 \\
06 \\
06 \\
05 \\
13 \\
44\end{array}$ & $\begin{array}{l}\text { TEMPO QUE CUIDA } \\
\qquad \begin{array}{l}\text { DO IDOSO } \\
\text { 1-3 anos } \\
4-6 \text { anos } \\
7-9 \text { anos } \\
10 \text { ou }+ \\
\text { Não soube referir }\end{array}\end{array}$ & $\begin{array}{l}22 \\
26 \\
08 \\
42 \\
02\end{array}$ \\
\hline $\begin{array}{l}\text { ESCOLARIDADE } \\
\text { Não alfabetizado } \\
\text { Primário Comp/Inc } \\
\text { Ens. Fund. } \\
\text { Comp/Inc } \\
\text { Ens. Médio } \\
\text { Comp/Inc. }\end{array}$ & $\begin{array}{l}30 \\
33 \\
19 \\
18\end{array}$ & $\begin{array}{l}\text { RELIGIÃO } \\
\text { Católico } \\
\text { Evangélico } \\
\text { Sem Religião }\end{array}$ & $\begin{array}{l}55 \\
33 \\
12\end{array}$ & $\begin{array}{c}\text { ESTADO CIVIL } \\
\text { Solteiro } \\
\text { Casado } \\
\text { Viúvo } \\
\text { Separado/Divorciado }\end{array}$ & $\begin{array}{l}34 \\
59 \\
03 \\
04\end{array}$ \\
\hline
\end{tabular}

Fonte: Questionário aplicado a familiares cuidadores de idosos hipertensos, residentes em um bairro periférico do município de Jequié-BA, 2004.

Constatamos, ainda, que é grande a proporção de idosos que cuidam de idosos. $\mathrm{O}$ fato de assumir essa tarefa perpassa questões morais, a ausência de descendentes ou por indisponibilidade dos filhos, devido à ocupação com as atividades laborais e com a prole. 
Os cuidadores com mais de 60 anos representam $50 \%$ dos homens (nove cuidadores) e $26,8 \%$ das mulheres ( 22 cuidadoras), quase que em sua totalidade em condição de conjugalidade, excetuando-se o cuidado entre irmãos e mãe-filho.

Outra variável que se destaca entre os cuidadores do estudo foi o estado civil. Das mulheres cuidadoras, 46 eram casadas e 30 eram solteiras, enquanto que dos homens, 13 cuidadores eram casados e apenas quatro eram solteiros.

Ao observarmos o grau de escolaridade, foi possível constatar que do total de cuidadores: 30 são analfabetos, 33 possuem o primário completo ou incompleto, 19 têm o ensino fundamental completo ou incompleto e 18 possuem o ensino médio concluído ou em curso. Ao relacionarmos o grau de escolaridade e a idade, constatamos que um maior nível de instrução é inversamente proporcional à idade dos cuidadores investigados.

Quanto à ocupação, grande parte das cuidadoras eram donas de casa (60\%), ou seja, apesar de desenvolverem seu trabalho por mais de 12 horas diárias, sem folga, não possuem remuneração. Em segundo lugar, estão os aposentados (10\%) e estudantes (10\%). Somente $4 \%$ dos cuidadores encontravam-se desempregados e $16 \%$ estavam inseridos no mercado informal.

Por se tratar de moradores de um bairro periférico, com baixa escolaridade e sem profissão de definida, a renda familiar média não ultrapassou três salários mínimos. A maioria (56) sobrevive com apenas um salário mínimo; 29, com recursos equivalentes a dois $\mathrm{e}$ até três salários mínimos; e oito têm renda familiar menor que um salário.

A relação de codependência é bem nítida. O recurso financeiro proveniente $d a$ aposentadoria do idoso ajuda na sobrevivência dos filhos e até mesmo dos netos. Em contrapartida, o cuidador auxilia os idosos nas atividades instrumentais, preparando as refeições, encaminhando-os aos serviços de saúde, encarregando-se dos serviços bancários, fazendo companhia, dentre outros.

Dos sujeitos participantes do estudo, 42 referiram cuidar do idoso hipertenso por dez anos ou mais, deixando claro que em alguns casos a hipertensão surgiu antes $\mathrm{da}$ sexta década de vida.

Quanto à situação de saúde/doença, 44 familiares cuidadores referiram não ter problemas de saúde e 24 afirmaram também ser hipertensos.

Com as informações obtidas por meio do TALP, aplicados aos 100 sujeitos pesquisados, obtivemos 369 palavras evocadas. As evocadas uma única vez foram desprezadas, obtendo uma análise mais "limpa". Assim, foram excluídas 13 palavras (3,5\%) e utilizadas 356 palavras $(96,5 \%)$, dentre as quais foram identificadas 30 distintas.

Os dados obtidos com o processamento foram organizados em um Quadro de Qua- 
tro Casas (Quadro 2), cujo ponto de corte considerado foi quatro, ou seja, não foram incluídas as palavras com frequência inferior a esta.

Quadro 2 - Quadro de quatro casas apresentando o núcleo central e o sistema periférico do cuidado familiar prestado a idosos hipertensos, Jequié - BA, 2004.

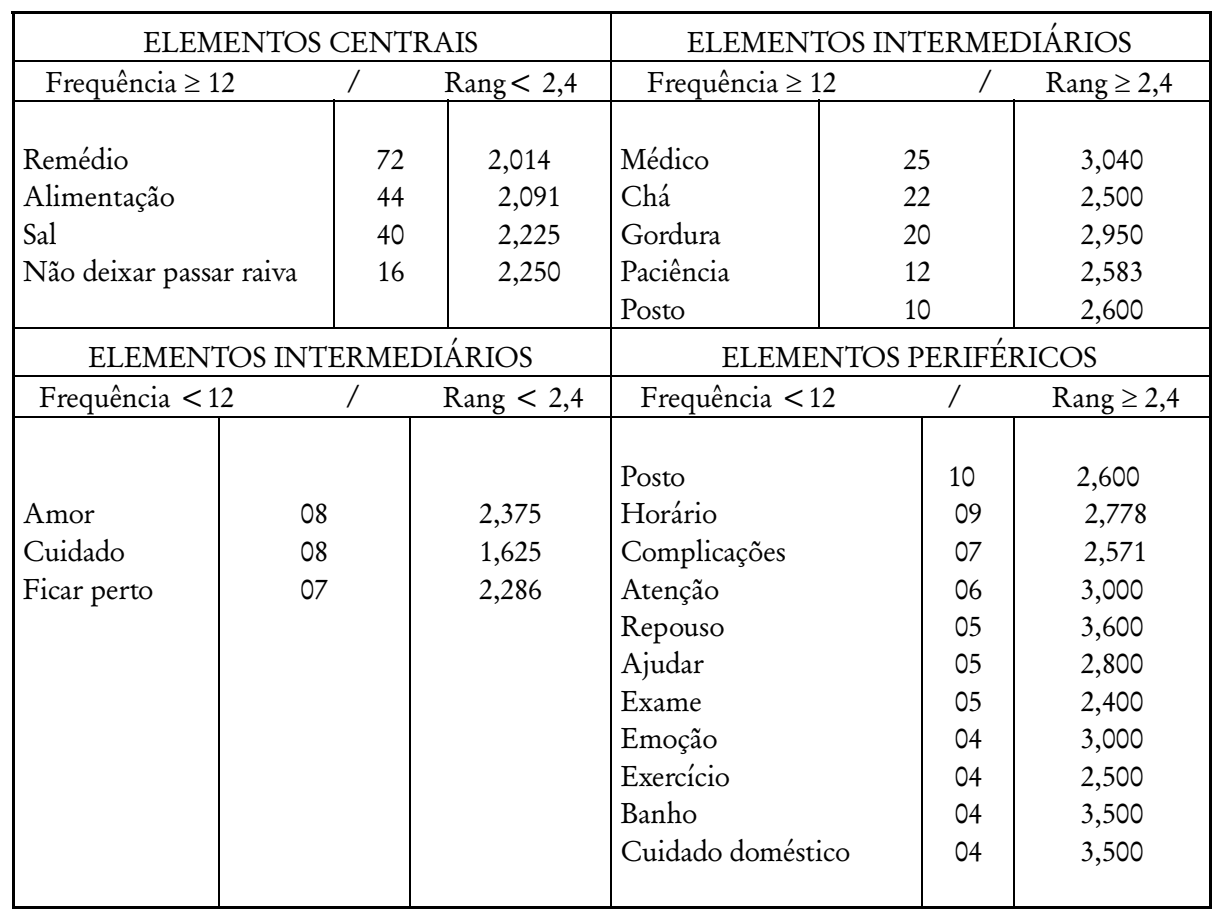

Para determinação do núcleo central e sistema periférico, foram consideradas a frequência e a média ponderada de ocorrência dos termos produzidos. A frequência diz respeito ao número de vezes que a palavra foi evocada, e a média ponderada refere-se à ordem de evocação estabelecida pelos sujeitos no processo cognitivo de hierarquização. A frequência e a ordem média de evocação calculadas e informadas pelo software foram, respectivamente, 12 e 2,4.
As palavras incluídas no quadrante superior esquerdo foram as mais frequentes $\left(\mathrm{F}^{3} 12\right)$ e as prioritariamente evocadas (Rang $<2,4)$; por isso, muito provavelmente, são os elementos constituintes do núcleo central da representação social do objeto em estudo.

Como podemos observar no quadro 2 , as palavras e expressões "remédio", "alimentação", "sal” e "não deixar passar raiva” são 
as mais frequentes e prioritariamente evocadas, constituindo, deste modo, os elementos que dão significação à representação do cuidado ao idoso com HA, na ótica de seus familiares cuidadores.

O termo "remédio" foi trazido à memória de 72 sujeitos, de um total de 100 participantes do estudo, sendo que, para 28 , foi prioritariamente evocado. Reflete a idéia dos familiares cuidadores em atribuir como cuidado prioritário lembrar o uso de anti-hipertensivos ou oferecer o medicamento de acordo com o grau de comprometimento da capacidade funcional do idoso. Remédio revelou-se como o elemento mais estável da representação do objeto.

Outro cuidado representado pelo grupo esteve relacionado à alimentação e à restrição do uso de sal. Essas práticas são relativas ao padrão alimentar a ser adotado pelo idoso hipertenso. Como vimos na caracterização dos sujeitos, as mulheres destacamse como cuidadoras principais de idosos hipertensos, cabendo-lhes, quase sempre, a compra e preparo dos alimentos não só para o idoso, mas para toda a família.

Apesar de os familiares cuidadores não possuírem o conhecimento científico sobre os mecanismos fisiológicos das emoções - como, por exemplo, a liberação de catecolaminas e seu efeito vasoconstritor em situações de apreensão -, a experiência cotidiana demonstra que a ocorrência do sentimento de raiva eleva a pressão arterial no idoso.
De acordo com as I Diretrizes Brasileiras em Cardiogeriatria, ${ }^{19}$ há evidencias do efeito do estresse psicoemocional na reatividade cardiovascular e da PA. Na prática, os familiares percebem que condições como a pobreza, a baixa autoestima, a inatividade, a viuvez e os conflitos familiares contribuem para o aumento da PA do idoso de forma transitória ou sustentada.

As palavras incluídas no quadrante inferior direito são representativas do sistema periférico, ou seja, tiveram frequência maior ou igual a quatro e menor que 12, e foram apontadas secundariamente no processo de hierarquização ( $\left.\operatorname{Rang}^{3} 2,4\right)$. Elas traduzem o que realmente é concretizado como cuidado ao idoso hipertenso, estabelecendo, assim, a interface com o núcleo central que sempre é consensual, mas nem sempre funcional. ${ }^{20}$

Foram apontados como elementos do sistema periférico: “ajudar", o que pode estar relacionado à percepção do familiar acerca do seu papel na vigência da HA no idoso. Isto nos mostra que parece circular entre os cuidadores a idéia de que o idoso é o responsável pelo seu autocuidado, cabendo a família ajudar, propiciar e facilitar o tratamento.

A palavra "atenção" pode estar relacionada à necessidade de o cuidador estar atento, alerta para quaisquer sinais de elevação súbita da PA, complicações, ou ainda ao horário da medicação. 
Os elementos banho e cuidados domésticos parecem estar associados ao apoio oferecido pelo cuidador nas atividades básicas $\mathrm{e}$ instrumentais da vida diária, quando o idoso apresenta capacidade funcional comprometida pelas complicações da HA, onde a mais frequente, no bairro estudado, é o AVE.

A palavra "emoção" revela a relação com a expressão "não deixar passar raiva”, pertencente ao núcleo central. Os cuidadores parecem evitar a ocorrência de emoções negativas para os idosos, na tentativa de ajudar no controle da HA, embora nem sempre isto seja possível.

Encontramos atitudes distintas concernentes à prática de atividade evidenciada nas palavras "exercício" e "repouso". Esses elementos representam atitudes de incentivo, ou não, dos cuidadores em relação à atividade física. Há indícios de que, para os cuidadores, o repouso pode estar restrito a idosos fragilizados, com complicações, que não tenham sido previamente submetidos a uma avaliação ou que apresentem queixa no dia e/ou horário da atividade, sendo, portanto, a atividade desmotivada pelos familiares. Repouso e exercício são elementos que não têm associação direta com o núcleo central. Acreditamos que eles dizem respeito à flexibilidade e individualidade dos elementos do sistema periférico.

Nas observações empíricas, percebemos que o repouso está vinculado a atividades com grande gasto energético ou exposição prolongada ao sol, já que a temperatura elevada é característica peculiar de Jequié, co- nhecida como a "Cidade Sol". Os cuidadores aconselham ou não permitem, a depender da condição do idoso, atividades como lavar roupas, limpar o quintal e deslocar-se em horários de maior intensidade solar, porque acreditam que atividades extenuantes associadas ao calor excessivo aumentam a pressão arterial.

Confirmamos a característica do sistema periférico quanto a sua funcionalidade, ou seja, seus elementos representam o julgamento que os sujeitos fazem referente ao cuidado com o idoso hipertenso, que pode ou não materializar-se em condutas. Sua função é concretizar o sistema central, cujos elementos são predominantemente normativos.

Desse modo afirmamos que, na ótica dos cuidadores familiares investigados, o cuidado ao idoso hipertenso se configura na forma de ajuda e atenção. Os elementos "sal" e "alimentação", pertencentes ao núcleo central, na prática se concretizam sob a forma de cuidados domésticos como a compra e preparo de alimentos recomendados para o idoso hipertenso. E o não deixar passar raiva, como a tentativa de evitar emoções negativas.

Observamos na periferia do sistema representacional que a palavra "horário" concretiza o elemento do núcleo central, "remédio". Pressupomos que os cuidadores consideram importante oferecer o medicamento prescrito, diariamente e na hora certa.

Palavras pertencentes aos quadrantes superior direito e inferior esquerdo estão in- 
cluídas entre os elementos do sistema intermediário. Percebemos que no quadrante superior direito, o elemento "médico" associa-se ao termo "remédio", uma vez que a este profissional é atribuída a competência legal para prescrever medicamentos. Quanto aos termos apresentados no quadrante inferior esquerdo, "amor" e "ficar perto", revelam a dimensão afetiva do cuidado ao idoso hipertenso.

Não obstante as recomendações da $\mathrm{SBC}^{19}$ serem de um atendimento ao idoso hipertenso, preferencialmente multidisciplinar, o suporte buscado, segundo as palavras evocadas pelo grupo, concentra-se na unidade de saúde e na pessoa do médico. Dentre outros fatores, a ocorrência de tal situação se dá pela competência legal do médico em prescrever o medicamento, elemento mais rígido da representação.

As informações circulantes no universo reificado (conteúdo peculiar às ciências), ao adentrarem no domicílio das famílias dos idosos hipertensos, ganham nova roupagem. Elementos são retirados, outros inseridos, uns esquecidos, outros acentuados. Os cuidadores, como grupo pensante, recebem, processam a informação e constroem novos significados, que lhes serão úteis na vida cotidiana.

Essa nova visão do cuidado na hipertensão retrata a relação que está estabelecida entre o idoso, o cuidador e o ambiente cultural, social e ideológico em que são gerados os comportamentos. Esse novo conhecimento não é apenas uma forma simplifi- cada de ver o objeto, mas é fruto de uma atividade construtiva, simbólica, que representa a forma de expressar dos cuidadores.

Não foram observadas evocações concernentes à restrição do uso do tabaco ou álcool. O fato é que, ao não mencionarem esses cuidados, os familiares cuidadores estabelecem uma construção seletiva, eliminando-os por problemas de difusão deste saber, por terem suas crenças fortalecidas a respeito do tabagismo e do uso do álcool, ou porque estes são hábitos que foram abandonados pelo idoso há muito tempo. Vemos, pois, que nesta construção seletiva, os critérios adotados são correspondentes ao contexto do grupo e atende a suas necessidades. ${ }^{19}$

Retomando a descrição de Moscovici, ${ }^{21}$ "[...] representar uma coisa, um estado, não consiste simplesmente em desdobrá-lo, repeti-lo ou reproduzilo", os cuidadores, ao elaborarem a representação do cuidado com o idoso hipertenso, filtraram e organizaram elementos, permanecendo aqueles que lhes são úteis no cotidiano.

Num sentido estrito, concordamos com $\mathrm{Vala},{ }^{22}$ ao afirmar que "[...] as RS alimentam-se não só das teorias cientificas, mas também dos grandes eixos culturais, das ideologias formalizadas, das experiências e das comunicaçôes cotidianas".22

\section{CONCLUSÃO}

Embora existam diretrizes que norteiam o tratamento de pessoas hipertensas, $\mathrm{o}$ ser idoso, em convívio familiar, morador 
de periferia e portador de doença crônica reserva peculiaridades importantes a serem consideradas pelos profissionais de saúde envolvidos no cuidado destes.

Estereótipos acerca da velhice, conflitos intergeracionais, problemas econômicos e questões culturais são influências constantes no pensar e no agir das pessoas que lhes são mais próximas - seus cuidadores familiares. Desse modo, os aspectos preconizados por especialistas ganham novo sentido. São reconstruídos, visando a atender necessidades reais, dando a este conhecimento elaborado uma conotação prática, mediante a organização, adaptação, criação de opiniões e conceitos acerca do objeto, que determinam atitudes diretivas próprias do indivíduo e de seu grupo de pertença.

Comprar, oferecer remédio, lembrar ou supervisionar seu uso são práticas frequentes na opinião dos cuidadores, seguindo-se a preocupação com a alimentação do idoso. Comprar, preparar, oferecer e estimular a aceitação faz parte do cotidiano das mulheres cuidadoras. A alimentação abrange não só a redução do teor de sal e gordura, mas também o oferecimento de nutrientes capazes de suprir as necessidades do ancião. Porém, nesse sentido, esbarram nas questões financeiras e culturais, lançando mão da criatividade para solucionar o problema.

Foi apontada pelos familiares a relação entre as emoções e a HA. Relacionaram nervosismo a hipertensão e a hipertensão ao nervosismo, ou seja, na visão do senso comum, o nervoso (agitação, ansiedade) é ao mesmo tempo causa e efeito da hipertensão. Sendo assim, é exigida uma qualidade imprescindível aos cuidadores: ser paciente. A paciência está em compreender as atitudes, nem sempre colaborativas do idoso, ajudando-o a superar momentos de crise ou ansiedade.

Outro cuidado revelado foi "não deixar o idoso passar raiva”. A contrariedade, geralmente provém dos conflitos familiares que se tornam mais constantes, devido aos arranjos familiares estabelecidos, a fim de ajudar financeiramente os filhos e netos.

Mediante tais considerações, é possível observar que a família tem se preocupado e se ocupado no cuidado de seus membros idosos hipertensos. Por isso, é de suma importância que os profissionais de saúde estabeleçam e/ou fortaleçam uma relação mais estreita de parceria com os familiares cuidadores, visualizando-os como colaboradores e clientes, uma vez que agregam hábitos de vida semelhantes aos dos idosos hipertensos sob seus cuidados. No entanto, mesmo reconhecendo que a participação do familiar no tratamento da HA no idoso oferece contribuições positivas, o autocuidado deverá ser sempre incentivado.

Cabe também aos profissionais de saúde valorizar, durante as consultas, a adoção de medidas não-medicamentosas, pois um estilo de vida saudável traz notórios benefícios também às pessoas idosas, prolongando a vida com autonomia e independência. 


\section{REFERÊNCIAS}

1. Instituto Brasileiro de Geografia e Estatística. Censo demográfico de 2000. [acesso 2003 ago 5]. Disponível em: URL: http:// www.ibge.gov.br/cidadesat/ index $2 . h t m l$

2. Kaiser SE. Hipertensão arterial: prevalência, significado, prognóstico e estagiamento. In: Couto AA; Kaiser SE. Manual de hipertensão da SOHERJ. São Paulo: Lemos Editorial; 2003.

3. Rede Interagencial de Informação para a Saúde - Ripsa. Indicadores básicos para a saúde no Brasil: conceitos e aplicações. 2ed. Brasília: OPAS; 2008.

4. Brandão $\mathrm{PB}$, et al. Hipertensão arterial no idoso. In: Freitas EV, et al. Tratado de Geriatria e Gerontologia. Rio de Janeiro: Guanabara Koogan; 2002.

5. Sociedade Brasileira de Hipertensão, de Cardiologia e de Nefrologia (SBH, SBC, SBN). V Diretrizes Brasileiras de Hipertensão Arterial. São Paulo, 2006.

6. Caputo MA, Torres T. Refletindo o processo Ensino-Aprendizagem nas Ações de Educação em Saúde. Manual para Treinamento Introdutório das Equipes de Saúde da Família. Salvador-BA; 2001.

7. Boehs AE. Construindo um marco conceitual e um processo de Enfermagem para cuidar de famílias em expansão. In: Elsen I, et al. Marcos para a prática de enfermagem com famílias. Florianópolis: Editora da UFSC; 1994. Série enfermagem - Repensul.

8. Leininger M. Transcultural nursing concepts theories and practices. New York: John Wiley \& Sons; 1978.

9. Gonçalves LHT, Alvarez AM.; Santos SMA. Os cuidadores leigos de pessoas idosas. In: Duarte YAO, Diogo MID. Atendimento domiciliar: um enfoque gerontológico. São Paulo: Atheneu; 2000.

10. Moscovici S. On Social Representation. In: Forgas JP. Social Cognition: perspectives on everyday understanding. Londres, Academis Press; 1981.

11. Jodelet D. Les Representations Sociales. 4. ed. Paris, Presses Universitaires de France; 1989.

12. Abric JC. L'étude expérimentale dês représentations sociales. In: Jodelet D, editor. Lês représentstions sociales. Paris: Presses Universitaires de France; 1989.

13. Brasil. Conselho Nacional de Saúde. Sobre a pesquisa envolvendo seres humanos. Resolução 196/96. [acesso em: 07 ago2003].Disponível em: URL: http:// www.fop.unicamp.br/cep/epi.pri.htm

14. Sá CP. A construção do objeto de pesquisa em representações sociais. Rio de Janeiro: EdUERJ; 1998

15. Caldas CP. Cuidando do idoso que vivencia uma síndrome demencial: a família como cliente da enfermagem. Texto \& Contexto Enfermagem 2001 maio/ago; 10(2): 68-93.

16. Santos SMA. Idosos, família e cultura: um estudo sobre a construção do papel do cuidador. Campinas, SP: Alínea; 2003.

17. Alvarez AM. Tendo que cuidar: a vivência do idoso e de sua família cuidadora no processo de cuidar e ser cuidado em contexto domiciliar. Florianópolis: UFSC; 2001.

18. Karsh UMS, organizador. Envelhecimento com dependência: revelando cuidadores. São Paulo: EDUC; 1998. 
19. Sociedade Brasileira de Cardiologia (SBC). I Diretrizes do Grupo de Estudos em Cardiogeriatria. Arquivos Brasileiros de Cardiologia 2002 jul; 79 (S1).

20. Wagner W. Sócio-gênese e características das Representações Sociais. In: Moreira ASP, Oliveira DC, organizadores. Estudos Interdisciplinares de Representação Social. Goiânia: AB; 1998.

Recebido: 20/10/2007

Reapresentado: 22/10/2008

Aprovado: 03/11/2008
21. Moscovici S. A representação social da Psicanálise. Rio de Janeiro: Zahar; 1978.

22. Vala J. Representações Sociais e Psicologia Social do conhecimento quotidiano. In: Vala J, Monteiro MAB, coordenadores. Psicologia Social. 4. ed. Lisboa: Serviço de Educação Fundação Calouste Gulbenkian; 2000. 